\title{
Prevalence of Gastrointestinal Nematodes and the Role of Allicin in Treatment of Cattle in Sharkia Governorate
}

Elshaima Mohamed Fawzi ${ }^{*}$ and Ibrahim Elsohaby

Animal Medicine Department, Division of Infectious Diseases, Faculty of Veterinary Medicine, Zagazig University, 44511, Egypt

\section{Abstract}

The objectives of this study were to investigate the prevalence of gastrointestinal nematodes (GIN) among cattle in Sharkia Governate, Egypt and to determine the efficacy of allicin as a treatment for GIN infection. Fecal samples $(\mathrm{n}=113)$ were collected randomly from cattle at different localities in Sharkia Governate between September 2016 and August 2018. Samples were then examined parasitologically. Overall, GIN were found in $21(18.6 \%)$ of the samples, the highest GIN prevalence was observed in winter (25.6\%), while the lowest prevalence was in summer $(10.3 \%)$. Adult cattle $(42.9 \%)$ showed higher GIN infection than young calves $(23.8 \%)$. Further, most of the infected cattle $(92.4 \%)$ showed a light intensity of infection with GIN. The coproculture of infected fecal samples reveled that, $15(71.4 \%)$ samples have single infection and $6(28.6 \%)$ samples have mixed infection and Trichostrongylus spp. (41.9\%) were the most frequently observed GIN, followed by Strongyloides spp. (35.2\%), whereas, Cooperia spp. $(8.7 \%)$ was the less frequently observed GIN. No significant difference $(P=0.78)$ was observed between using albendazole and allicin for treatment of GIN in cattle. The current study provides new and updated results that may help in the effort to control GIN. Also, this study shows that allicin could be used for treatment and control of GIN in cattle. However, further investigations in the efficacy of allicin in treatment of GIN in cattle and actual dose, are warranted.

Keywords: Gastrointestinal Nematodes, Allicin, Cattle, Egypt.

\section{Introduction}

Cattle production in Egypt especially Sharkia Governorate is one of the most important sources of milk and meat production. In Egypt, production levels are low because of poor nutrition, management and infestation with gastrointestinal nematodes (GIN) [1]. Although, poor nutrition is considered the most critical factor, infestation with GIN constitute a major source of economic loss represented in decrease weight gain, meat quality, milk yield and cost of treatment. Furthermore, the loss due to the cost of resistant produced from the misuse of anthelmintic [2-4]. GIT infestation reduces feed intake, protein and energy retention. Also, disturbed mineral, water balance and change gastrointestinal motility leading to diarrhea [5]. The most recorded species of GIN of ruminants are Trichostrongylus spp., Haemonchus spp., Ostertagia spp., Oesophagostomum spp., Cooperia spp., Trichuris spp., Bunostomum spp., etc. [6]. Several diagnostic methods were used for assessment of the prevalence and treatment of different GIN such as the individual fecal examination, determination of egg per gram

*Corresponding author email: (elshaimafawzi@yahoo.es), Animal Medicine Department, Division of Infectious Diseases, Faculty of Veterinary Medicine, Zagazig University, 44511, Egypt.
(EPG) and identification of specific species of nematodes [7].

Recently, several types of anthelmintic drugs have been used to control GIN in ruminants, such as albendazole which inhibit tubulin polymerization [8]. However, the inadequate use of anthelmintic drugs reduced production level and increased parasites resistance, moreover, the long withdrawal time lead to appearance of chemical residues in milk [9]. Therefore, there is a need for alternative methods such as biological control or using medicinal plant like garlic in which the allicin is considered as the active principle [10]. Allicin (diallyl thiosulfinate = 2-Propene1-sulfinothioic acid S-2-propenyl ester) has shown a wide remedy effect as an antimicrobial, antifungal, antiprotozoal and antiparasitic [11]. Allicin is a natural product present in plants of the Family Alliaceae and has shown anthelmintic effect in both in vitro against Haemonchus contortus [12] and in vivo against Strongyloides spp. in donkey [13]. The essential mechanism of action of allicin is correlated to its high permeability through cell membranes and rapid interaction with thiols in addition to wide safety margin. Therefore, 
allicin does not only affect intercellular parasites but also intracellular ones [14]. The objectives of the present work were to determine the current prevalence of GIN in cattle in Sharkia Governate and to determine the efficacy of allicin as an anthelmintic in cattle.

\section{Material and methods}

\section{Sampling}

Between September 2016 and August 2017, 113 fecal samples were collected randomly from diarrheatic cattle in Sharkia Governate. The samples were collected from 3 regions in (Zagazig [Veterinary hospital] (42 cases), Diarb Negam (45 cases), Menia El-kamh (26 cases)). Individual fecal samples were taken directly from the rectum using plastic hand gloves. Each sample was labeled with cattle identity number, date of sampling, age, and sex, and then they were transferred to the laboratory for examination. The study protocol was approved by the Animal Welfare and Research Ethics Committee of Faculty of Veterinary Medicine, Zagazig University, Egypt.

\section{Faecal Egg Counts (FEC)}

Fecal samples (50 - 100 g) were macroscopically inspected for the presence of nematode eggs and larvae. Samples were then processed for microscopical examination by a modified McMaster technique [15]. The FEC was conducted under the light microscope, at $\times 100$ and $\times 400$ magnifications and presented as egg per gram (EPG). The FEC was categorized according to the degree of infection intensity into three categories: $\mathrm{EPG}=$ 0 - 200 (light infection); 200 - 400 (moderate infection) and $>800$ (heavy infection) [16].

\section{Faecal Culture}

Fecal samples with GIN eggs were homogenized and disintegrated with tap water. Samples were then incubated in $1000 \mathrm{~mL}$ plastic containers at $22-26^{\circ} \mathrm{C}$ for 10 days. The cultures were removed daily and aerated. The Baermann technique was used to separate the larvae (L3) from the fecal material. The larvae were then cleaned and stored at $4{ }^{\circ} \mathrm{C}$ in tap water until examined (within one week of collection of larvae) [15]. A drop of suspected larval suspension was pipetted out from the collected container and transferred into a glass slide. It was then gently heated to immobilize and gradually kill the larvae to facilitate examination and cover slide was then put over it. The cover slides were sealed with molten paraffin to avoid evaporation. The larvae were then examined under a light microscope and identified based on studying the morphological characters and measurements of various parts of the body (such as size and tail sheath length). In mixed infection, 100 L3 were randomly selected and characterized, then the average of each GIN species was calculated according to Soulsby [17].

\section{Treatment Trials}

Nine naturally infected cattle with moderate and light intensity of infection and within the age groups ranged from 2-3 years were randomly assigned into three groups (each group included 3 cattle). Group 1: a single dose of $10 \mathrm{mg} / \mathrm{kg}$ albendazole (OS: BAN, DCF, JAN, USAN) was administered orally to the animal. Group 2: a single dose of $10 \mathrm{mg} / \mathrm{kg}$ of allicin (AllicinMax ${ }^{\mathrm{TM}}$ from Allicin International Ltd, Rye, East Sussex, UK) was administered orally to the animal. Group 3: a mixed suspension of $10 \mathrm{mg} / \mathrm{Kg}$ albendazole + $100 \mathrm{mg} / \mathrm{kg}$ of allicin was administered orally to the animal. Individual fecal samples were collected from each animal in each group at days $0,7,14$ and 21 post-treatment. The FEC was then performed as described above. The efficacy of each drug was evaluated by calculating the reduction in GIN eggs count on the $7^{\text {th }}, 14^{\text {th }}$, and $21^{\text {th }}$ days post-treatment by using this formula:

$\%$ ofreduction $=$ AverageEPGday $0-$ AverageEPGday $(7$ or 14 or 21$) \times 100$

\section{AverageEPGdayO}

\section{Statistical Analysis}

Statistical analysis was performed using STATA 15 (StataCorp, College Station, TX) to determine whether there were any significant differences $(\mathrm{P}<0.05)$ in the GIN eggs count between the three groups using One-way ANOVA. 
Table 1: Seasonal infection rate of affected cattle with gastrointestinal nematode eggs at different localities in Sharkia Governate between September 2016 and August 2018

\begin{tabular}{|c|c|c|}
\hline Season & No. of examined cattle & No. of positive cattle $(\%)$ \\
\hline Winter & 39 & $10(25.6)$ \\
\hline Spring & 26 & $5(19.2)$ \\
\hline Summer & 29 & $3(10.3)$ \\
\hline Autumn & 19 & $3(15.7)$ \\
\hline Total & 113 & $21(18.6)$ \\
\hline
\end{tabular}

Table 2: Incidence of infection with gastrointestinal nematodes (GIN) in young and adult cattle at different localities in Sharkia Governate between September 2016 and August 2018. Samples

\begin{tabular}{lcc}
\hline Age & No. of examined cattle & No. of positive cattle (\%) \\
\hline Young (<1 year) & 30 & $5(23.8)$ \\
Adult (1-2 years old) & 28 & $4(19)$ \\
Adult $(\mathbf{2 - 3}$ years old) & 34 & $9(42.9)$ \\
Adult $(>\mathbf{3}$ years old $)$ & 21 & $3(14.3)$ \\
\hline
\end{tabular}

\section{Results}

One hundred and thirteen faecal samples were collected and tested for gastrointestinal nematodes (GIN) infection. Clinical examination showed that 35 animals had high temperature $\left(39.7-40.2^{\circ} \mathrm{C}\right)$ and the remaining 78 animals showed normal temperature (38.5 $\left.39{ }^{\circ} \mathrm{C}\right)$. The mucous membrane varied from normal rose red to pale and in rarly congested, normal lymph nodes upon inspection, with alert animals in standing position (70 animals) and rest of examined one wre dull and depreesed while still in standing position, slight increase in both respiratory and heart rate were noticed.

Using faecal examination, the prevalence rate of infection with gastrointestinal nematodes was $18.6 \%$ (21 infected cases out of 113 examined one). The highest infection rate was recorded in Winter $(25.6 \%)$, followed by Spring (19.2\%) and Autumn (15.7\%), while the lowest rate was recorded in Summer (10.3\%) (Table1). Moreover, the highest rate of infection with GIN recorded in adult cattle with 2-3-year-old $(42.9 \%)$ than calves with < one-year-old (23.8\%) (Table 2). The intensity of infection with GIN in infected cattle was graded into three degrees and presented in Table 3. Most of the infected cattle $(92.4 \%)$ showed a light intensity of infection with GIN. The coproculture of infected faecal samples reveled that, $15(71.4 \%)$ samples had single infection and $6(28.6 \%)$ samples had mixed infection (Table 4). The most identified type of GIN was Trichostrongylus spp. (41.9\%), followed by Strongyloides spp. (35.2\%), Haemonchus spp. (29.7\%) and Osephagostomum spp. (14.8\%), whereas, Cooperia spp. (8.7\%) was the less frequently observed GIN. 
Table 3: Intensity degrees of gastrointestinal nematodes (GIN) infection in cattle at different localities in Sharkia Governate between September 2016 and August 2018. Samples

\begin{tabular}{lcc}
\hline Number of egg per gram & $\%$ & Intensity of infection \\
\hline $\mathbf{0 - 2 0 0}$ & $92.4 \%$ & Light \\
$\mathbf{2 0 0 - 8 0 0}$ & $6.3 \%$ & Moderate \\
$\mathbf{8} \mathbf{8 0 0}$ & $1.3 \%$ & Heavy \\
\hline
\end{tabular}

Table 4: Proportion of gastrointestinal nematode infection obtained from coproculture of fecal samples

\begin{tabular}{lc}
\hline Type of nematode detected & Frequency (\%) \\
\hline Single infection & $6(40)$ \\
\hline Trichostrongylus spp. & $3(20)$ \\
Strongyloides spp. & $3(20)$ \\
Haemonchus spp. & $2(13.3)$ \\
Oesphagostomum spp. & $1(6.7)$ \\
Cooperia spp. & $\mathbf{1 5}(\mathbf{7 1 . 4 )}$ \\
Sub total &
\end{tabular}

\begin{tabular}{lc}
\hline Mixed infection & \\
\hline Trichostrongylus spp. + Haemonchus spp. & $2(33.4)$ \\
Trichostrongylus spp. + Strongyloided spp. & $1(16.6)$ \\
Haemonchus spp. + Strongyloides spp. & $1(16.6)$ \\
Strongyloides spp. + Oesphagostomum spp. & $1(16.6)$ \\
Strongyloides spp. + Cooperia spp. & $1(16.6)$ \\
Sub total & $\mathbf{6}(\mathbf{2 8 . 6 )}$ \\
\hline Total & $\mathbf{2 1 ( \mathbf { 1 8 . 6 } )}$ \\
\hline
\end{tabular}

The efficacy of treatment (albendazole and allicin) in different groups were illustrated in Figure 1. Albendazole and the combination of both albendazole and allicin reduced number of GIN's eggs to 0 at day 21 post-treatment. However, no significant difference $(\mathrm{P}=0.78)$ were detected between using albendazole, allicin and the combination of albendazole and allicin for treatment of GIN in cattle.

\section{Discussion}

In the present study, the prevalence of GIN infection was $18.6 \%$, which was similar to $20.5 \%$ report by Muraleedharan [18]. However, this prevalence is low compared 
with $46.6 \%$ reported by Jittapalapong [19], $49 \%$ recorded by Bacha [20] and 52.9\% recently observed by Kemal [21]. The difference in the prevalence rates might be attributed to variation in geographical locality, climatic condition present, management system, age and breed of animals and technique used to detect the GIN eggs [22]. In the current study, the highest infection rate was observed in winter, while the lowest infection rate was recorded in summer. Similar results were recorded in previous studies $[19,23]$ and was attributed to that rainy season allows the survival of parasite. Other studies have reported high infection rates in summer than winter in contrast to the present study and attaributed to the high temprture and humidity stress [24,25]. Further, in the present study, lower prevalence of GIN was found in young calves ( $<$ one-year-old) than that in adult cattle (2-3-year-old). Similar results were previously reported in adult cattle, explaining the correlation by the high chance of exposure to a source of infection with age increase [19,25]. Other studies have reported higher prevalence of GIN in young calves than older cattle, which might be due to the ill developed immune system (more susceptible) of young calves [26,27]. Most of the cattle involved in this study showed a low intensity of GIN infection (92.6\%). This finding is consistent with some studies [26,27]. However, a recent study reported a moderate degree of parasitism [21]. The coproculture of infected faecal samples reveled that $15(71.4 \%)$ samples had single infection and $6(28.6 \%)$ samples had mixed infection, which is consistent with previously published studies $[21,28]$. In this study, Trichostrongylus spp. (41.9\%), Strongyloides spp. (35.2\%) and Haemonchus spp. (29.7\%) were the most frequently observed GIN. A similar finding was reported in ruminants but with slight difference in the predominant genera $[26,29,30]$.

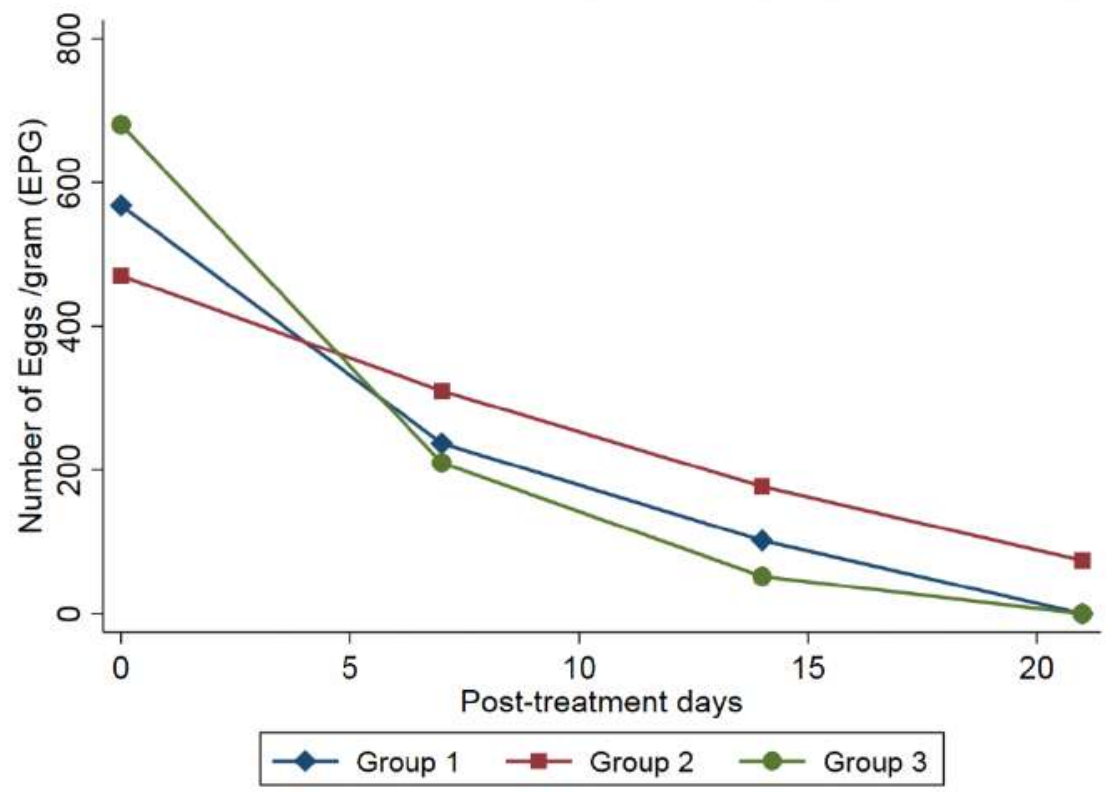

Figure 1: Mean faecal egg count per gram (EPG) of animals treated by Albendazole (Group 1), Allicin (Group 2) and the combination of Albendazole and Allicin (Group 3). 
In spite of numerical difference observed in fecal egg count between treated groups but not statically significant $(\mathrm{p}>0.05)$, there was a negative correlation between mean fecal egg count in each group and the days posttreatment. The decrease of EPG without complete elimination until day 21 posttreatment was observed in group 2 treated with allicin and complete reduction of EPG to zero was seen at day 21 post-treatment in both group 1 and 3. In the present study, the efficacy of albendazole in treatment of GIN was $100 \%$, which is similar to the results previously reported in other studies [30-33]. However, one study has restricted the efficacy of albendazole until the day 28 post-treatment [28] and other studies have reported some degree of resistance to albendazole [34,35]. Furthermore, allicin reduced the mean of FEC at day 21 post-treatment by $84 \%$. This finding was in disagreement with a previous study [36], who reported no effect for allium sativum on GIN of experimentally infected sheep. On the other hand, Batatinha [37] reported partial control of nematodes infection in adult goats and Masamha [38] found reduction in EPGs of sheep infected with Strongyloides spp. and Trichostrongylus spp. after administration of garlic. Other studies reported that garlic has no effect when used in an herbal product against Haemonchus contortus in lambs $[39,40]$. Also Burke [40] demonstrated that no effectiveness of a commercially available certified organic garlic product, fresh garlic juice, or garlic bulbs as an anthelmintic to control the infection of GIN in goat was observed. Furthermore, garlic alcoholic tincture showed no effect on gastrointestinal infection in sheep in both treated groups with $40 \mathrm{~g}$ and $60 \mathrm{~g}$ of product in both 7 and 14 days post-treatment [36].

\section{Conclusion}

The prevalence of GIN infection in cattle in Sharkia Governate, Egypt was recorded in this study and that allicin could be used for treatment of GIN infection in cattle. However, further investigations in the efficacy of allicin in treatment of GIN in cattle and actual dose, are encouraged.

\section{Conflicto $f$ interest}

The autors declare no conflict of interest.

\section{Acknowledgements}

The authors thank farmers who participated in this work and technicians for their excellent laboratory assistance and data collections. This work was performed using the facilities of Faculty of Veterinary Medicine, Zagazig University.

\section{References}

[1] Khalafalla, R.E.; Elseify, M.A. and Elbahy, N.M. (2011): Seasonal prevalence of gastrointestinal nematode parasites of sheep in northern region of Nile Delta, Egypt. Parasitol Res, 108(2):337-40.

[2]Oliveira, M.; Alencar, M.; Giglioti, R.; Beraldo, M.; Aníbal, F.; Correia, R.; Boschini, L.; Chagas, A.C.S.; Bilhassi, T.B. and Oliveira, H.N. (2013): Resistance of beef cattle of two genetic groups to ectoparasites and gastrointestinal nematodes in the state of São Paulo, Brazil. Vet Parasitol, 197(1):168-75.

[3]Rinaldi, M. and Geldhof, P. (2012): Immunologically based control strategies for ostertagiosis in cattle: Where do we stand? Parasite Immunol, 34(5):254-64.

[4] Charlier, J.; Höglund, J.; von SamsonHimmelstjerna, G.; Dorny, P. and Vercruysse, J. (2009): Gastrointestinal nematode infections in adult dairy cattle: Impact on production, diagnosis and control. Vet Parasitol, 164(1):70-9.

[5] Blackburn, H.; Rocha, J.; Figueiredo, E.; Berne, M.; Vieira, L.; Cavalcante, A. and Rosa, S. (1991): Interaction of parasitism and nutrition and their effects on production and clinical parameters in goats. Vet Parasitol, 40(1-2):99-112.

[6]Samanta, A.; Santra, P.K. (2007): Prevalence of gastrointestinal helminths in hot and humid zone of West Bengal. J Vet Parasitology, 21(2):145-8.

[7] Urquhart, G.; Armour, J.; Ducan, J.; Dunn, A. and Jennings, F. (1996): Veterinary 
parasitology, black well science. United Kingdom, 307.

[8]Dale, M. and Haylett, D. (2004): Pharmacology condensed. 1st edn., chirchill livingston.

[9]Lopes, W.D.Z.; dos Santos, T.R.; Sakamoto, C.A.; de Lima, Roberto Cesar Araújo, Valarelli R.L.; Paiva, P. and da Costa, J. (2013): Persistent efficacy of $3.5 \%$ doramectin compared to $3.15 \%$ ivermectin against gastrointestinal nematodes in experimentally-infected cattle in Brazil. Res Vet Sci, 94(2):290-4.

[10] Ahmed, M.; Laing, M.D. and Nsahlai, I.V. (2014): In vivo effect of selected medicinal plants against gastrointestinal nematodes of sheep. Trop Anim Health Prod, 46(2):411-7.

[11]Cañizares, P.; Gracia, I.; Gómez, L.A.; García, A.; de Argila, C.M.; Boixeda, D. and de Rafael, L. (2004): Thermal degradation of allicin in garlic extracts and its implication on the inhibition of the invitro growth of Helicobacter pylori. Biotechnol Prog, 20(1):32-7.

[12]Chybowski J. (1997): Study of the anthelmintic activity of garlic extracts. Herba Pol, 43:383-7.

[13]Sutton, G. and Haik, R. (1999): Efficacy of garlic as an anthelmintic in donkeys. Isr J Vet Med, 54:23-7.

[14]Miron, T.; Rabinkov, A.; Mirelman, D.; Wilchek, M. and Weiner, L. (2000): The mode of action of allicin: Its ready permeability through phospholipid membranes may contribute to its biological activity. Biochim Biophys Acta Biomembr, 1463(1):20-30.

[15]Britain G. Ministry of agriculture, fisheries and food. manual of veterinary parasitological laboratory techniques. Tech.Bull 1971(18).

[16]Hansen, J. and Perry, B. (1994): The Epidemiology, Diagnosis and Control of Helminth Parasites of Ruminants. A Handbook.

[17]Soulsby E. (1972): Helminths, Arthropods and Protozoa of Domesticated Animals (6th Ed. of MSnnig's Veterinary Helminthology and Entomology).

[18] Muraleedharan, K. (2005): Prevalence of gastrointestinal parasites of livestock in a central dry zone of Karnataka. J Vet Parasitol, 19(1):31-3.

[19]Jittapalapong, S.; Sangwaranond, A.; Nimsuphan, B.; Inpankaew, T.; Phasuk, C.; Pinyopanuwat, N.; Chimnoi, W.; Kengradomkij, C.; Arunwipat, P. and Anakewith, T. (2011): Prevalence of gastro-intestinal parasites of dairy cows in Thailand. J Nat Sci, 45:40-5.

[20] Bacha, A. (2014): Study on prevalence of gastrointestinal nematodes and coccidian parasites affecting cattle in west Arsi zone, Ormia regional state, Ethiopia. Global J Anim Sci Res, 3(1):77-86.

[21]Kemal, J.; Muktar, Y. and Hiko, A. (2017): Major gastrointestinal nematodes of cattle in Dire Dawa adminstration, Eastern Ethiopia. Livest Res Rural Dev, 29:1-10.

[22]Cawthorne, R. (1984): Anthelmintics for cattle, sheep, goats, pigs, horses and poultry. MAFF publication Lion house, Willowbum estate, Alinwick.

[23]Ilyas, N.; Hossain, M.; Bhuyan, M. and Khan, M. (2016): Prevalence of gastrointestinal nematodes infection of cattle in Bangladesh. Am J Phytomed Clin Therapeut, 4(3):091-7.

[24]Al-Aboody, M.S. and Omar M.A. (2016): Prevalence of gastrointestinal nematodes of farm animals by copro-culture. Russ $\mathbf{J}$ Parasitol, 2(36)168-174.

[25] Sreedevi, C. and Hafeez, M. (2014): Prevalence of gastrointestinal parasites in buffaloes (Bubalus Bubalis) in and around Tirupati, India. Buffalo Bull, 33(3):251-5.

[26]Pfukenyi, D.M.; Willingham, A.; Mukaratirwa, S. and Monrad, J. (2007): Epidemiological studies of parasitic gastrointestinal nematodes, cestodes and coccidia infections in cattle in the highveld and lowveld communal grazing areas of Zimbabwe. Onderstepoort J Vet Res, 74(2):129-42. 
[27]Kemal, J. and Terefe, Y. (2013): Prevalence of gastrointestinal parasitism of cattle in Gedebano Gutazer Wolene district, Ethiopia. J Vet Med Anim Health, 5(12):365-70.

[28]Islam, M.M.; Islam, M.S.; Howlader, M.M.R. and Lucky, N.S. (2015): Prevalence of gastrointestinal nematodiasis and comparative efficacy of anthelmintics on body weight of cattle in Bangladesh. Int J Sci Res Agric Sci, 2:61-75.

[29]Silva, J.B.; Rangel, C.P.; Fonseca, A.H. and Soares, J.G. (2012): Gastrointestinal helminths in calves and cows in an organic milk production system. Rev Bras Parasitol Vet, 21(2):87-91.

[30]González-Garduño, R.; Arellano, M.L.; de Gives, P.M.; García, J.A.; MarieMagdeleine, C.; Hernández, G.T.; Hernández, J.O. and Hinojosa-Cuéllar, J.A. (2017): Comparative response of IgA and IgG activity and hematological parameters among four main beef-cattle breeds infected with gastrointestinal nematodes in the warm humid tropic of Mexico. Ann Anim Sci, 17(3):819-33.

[31]Alsaad, K. and Al-Iraqi, O. (2010): Comparison of theraputical efficacy of albendazol, levozan and ivermectine in treatment of buffaloes naturally infected with gastro-intestinal worms in Mosul, Iraq. Buffalo Bull, 20:189-93.

[32]Demeler, J.; Van Zeveren, A.; Kleinschmidt, N.; Vercruysse, J.; Höglund, J.; Koopmann, R.; Cabaret, J.; Claerebout, E.; Areskog, M. and von Samson-Himmelstjerna, G. (2009): Monitoring the efficacy of ivermectin and albendazole against gastro intestinal nematodes of cattle in Northern Europe. Ve Parasitol, 160(1):109-15.

[33] Nwosu, C.O.; Eneme, T.A.; Onyeyili, P.A. and Ogugbuaja, V.O. (2008):
Toxicity and anthelmintic efficacy of crude aqueous of extract of the bark of Sacoglottis Gabonensis. Fitoterapia, 79(2):101-5.

[34]Hoque, M.; Begum, N. and Nooruddin, M. (2003): Albendazole resistance in gastrointestinal nematode parasites of cattle in Bangladesh. Trop Anim Health Prod, 35(3):219-22.

[35]Sissay, M.M.; Asefa, A.; Uggla, A. and Waller, P.J. (2006): Anthelmintic resistance of nematode parasites of small ruminants in Eastern Ethiopia: Exploitation of refugia to restore anthelmintic efficacy. Vet Parasitol, 135(3):337-46.

[36]Santos, F.C.C. and Carvalho, N.U.M. (2014): Alcoholic tincture of garlic (allium sativum) on gastrointestinal endoparasites of sheep-short communication. Ciência Anim Brasileira, 15(1):115-8.

[37] Batatinha, M.J.; Botura, M.B.; Santos, M.M.; Silva, A.; Almeida, M.D.; Santana, A.F.; Bittencourt, T.C. and Almeida, M.A. (2004): Efeitos do suco de alho (allium sativum linn.) sobre nematódeos gastrintestinais de caprinos.

[38]Masamha, B.; Gadzirayi, C. and Mukutirwa, I. (2010): Efficacy of allium sativum (garlic) in controlling nematode parasites in sheep. Int $\mathbf{J}$ Appl Res Vet Med, 8(3).

[39]Burke, J.; Wells, A.; Casey, P. and Miller, J. (2009): Garlic and papaya lack control over gastrointestinal nematodes in goats and lambs. Vet Parasitol, 159(2):171-4.

[40]Burke, J.; Wells, A.; Casey, P. and Kaplan, R. (2009): Herbal dewormer fails to control gastrointestinal nematodes in goats. Vet Parasitol, 160(1):168-70. 


\section{الملخص العربي}

دراسه عن معدل انتشار الديدان المعوية في المواشي في محافظة الثرقيه مع التطرق الي دور الاليسين في العلاج

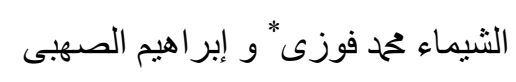

$$
\text { قسم طب الحيو ان (الأمر اض المعدية)_كلية الطب البيطري- جامعة الزقازيق }
$$

الهدف من هذه الدراسة هو التعرف علي معدل انتشار الديدان المعوية بين المواشي في محافظة الثرقيه بمصر وتحديد فئ فعالية

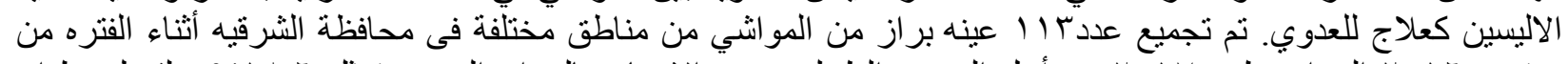

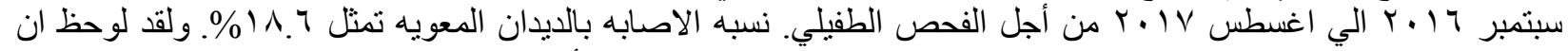

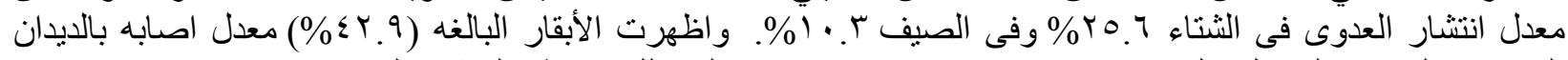

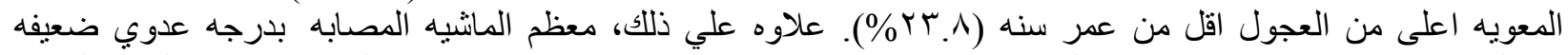

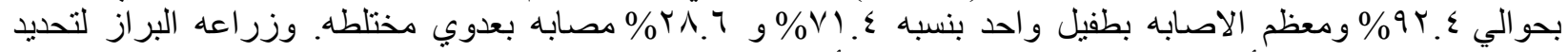

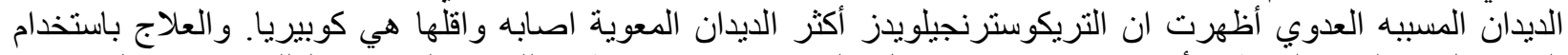

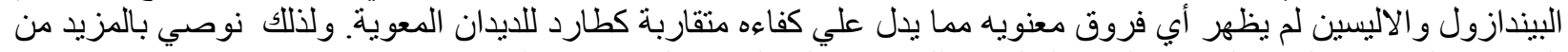

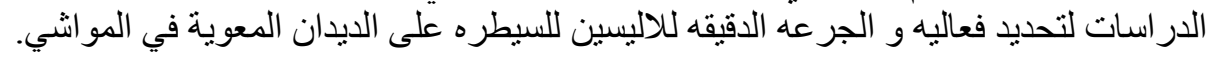

